\title{
Structural Modelling to Study the Role of Attitude and Risk Taking Behavior
}

\author{
${ }^{1}$ Rail M. Shamionov, ${ }^{2}$ MarinaV.Grigoryeva \\ ${ }^{1,2}$ Saratov State University, 410012 Russia, Saratov, Astrakhanskaya st., 83 \\ shamionov@info.sgu.ru, grigoryevamv@mail.ru
}

Received: 17th May 2020, Accepted: 18th June 2020, Published: 31st August 2020

\begin{abstract}
Social activity of young people is the condition for social and personal development. In this study we set the role of attitudes and proneness to risk in young people's social activity. 305 people aged $\mathrm{M}=21.2, \mathrm{SD}=2.95$ ( $35.4 \%$ men; $64.6 \%$ women) took part in the study. As a result of the study we have found out that socially oriented activity is one of the tools for fulfillment of the need for new impressions. The degree of manifestation of socially oriented activity is positively correlated with the number of friends; emotional, motivational and behavioral components of social activity are positively correlated with the participation of young people's parents in social life of their country and their personal civil identity. Based on structural modeling, we came to the conclusion that the following things are important for manifestation level of general activity (1) coordinated effect (influence) of attitudes regarding the possibility of social activity in the country and socially oriented activity, and (2) age effect (negatively) and socially oriented activity through the tendency to risky behavior independent of each other.
\end{abstract}

\section{Keywords \\ Personality, Young People, Social Activity, Risk, Identity, Socialization.}

\section{Introduction}

Personal social activity is an important characteristic of a modern person. It is an effect of socialization [1] and a tool for achievement [2], as well as the criterion for successful self-fulfillment in the modern world [3]. The studies of psychological characteristics and social activity factors, which have been conducted over the last decades prove that it is poly-directional [4] and highly-intensive in certain periods of life. High significance is given to life periods, where there is either almost no work-related activity or it is not of primary importance yet. These periods are youth, adolescence $[3 ; 5]$ and old age $[6 ; 7 ; 8]$. Social activity plays the leading role in a person's social life and conditions his/her socialization during these periods of life.

Theoretical analysis of the phenomenon of social activity shows that it is human activity, which is fulfilled due to building a link between a person and objects/subjects of the social world, which results in changes in these instances. That is why social activity is perceived as an initiative-based influence of social subjects on the surrounding environment, other people and oneself, which reproduces or changes the conditions of their life activity, and develops their own organizational structure and psyche [9].

The study of personal social activity mostly involves the period of youth. Extensive studies which have been conducted over the last decades are related to analysis of students' social activity as a special form of socialization [10]. Socialization is viewed from the point of view of developing various social skills and practices, including social self-identification [11], communicative and organizational skills, prosocial behavior skills [3], as well as political and civil participation [12;13]. Another important issues are social activity in the Internet-network sphere [14], as well as the influence of Internet-network communities on the activity implemented in real life $[15 ; 16$; 17]. When applied to later stages of personal socialization, studies of social activity touch upon issues of its organization [8], as well as the correlation between social activity and psychological/psycho-psychological safely $[18 ; 19]$. We view social activity as a permanent phenomenon, which has various levels of intensity during different life periods. That is why, within studies of social activity and its factors we have to introduce the age variable as the major variable not only from the point of view of chronology, but from the point of view of individual socialization and development of social experience as well.

An important area for social activity studies is the analysis of its social and psychological factors, within which the following is of major importance in the degree of manifestation of various forms of social activity: values [5], convictions [20], characteristics of social role in the activity, as well as the role of the mass media [21], social networks on the Internet [22].

Despite the fact that there is a relatively big number of studies in this scientific area, there is an extensive problem field of personal and group social activity, which can be investigated. This investigation allows to define its more important stable and changeable characteristics, as well as the essential variables - factors, which are quite sensitive to milestone events in the social life.

Culture and social environment are significantly important for social activity [4]. They set important guidelines that act as regulators of young people's behavior and acquisition of the role of regulators by various personal 
entities, including proneness to risk, obviously depends on them. Therefore, the purpose of this study is to investigate the role of attitudes and proneness to risk as socialization effects in individual social activity.

We suppose that social attitudes and proneness to risk have an immediate and circumstantial influence on the variations of general social activity of young people.

The purpose of the study is:

To perform correlation analysis of variables and trace the connections between them;

To design a SEM-model of paths for attitudes, proneness to risk and social activity characteristics.

\section{Materials and Methods}

In the course of the study we used the questionnaire to record social and demographic characteristics and developed scales aimed at measuring adherence to a particular type of social activity (scale dimension - 5 points according to Lakert scale): Altruistic activity (AA), Leisure activity (LA); Socio-political activity (SPA); Internet network activity (INA); Civil activity (CA); Socio-economic activity (SEA); Educational Development Activity (EDA); Spiritual activity (SA); Religious activity (RA); Protest activity (PA); Radical Protest Activity (RPA); Subcultural activity (SA). We obtained common activity scale based on the calculation of the arithmetic mean. The scales have been developed based on the studies of ideas about social activity. All scales have an acceptable level of reliability: $\alpha$ Cronbach $=0.68-0.74$.

To define the components of socially-oriented activity, we used the questionnaire called "Components of sociallyoriented activity" [23], which presupposes evaluation of four components, i.e. cognitive, emotional-status, motivational, and behavioral. All the scales have acceptable reliability level $\alpha$ Cronbach $=0.72-0.78$.

To assess the level of manifestation of social attitudes, we introduced scales (scale dimension - 5 points according to Lakert scale). For example, "try to assess to what extent the country gives opportunities for participation in public life and manifestation of social activity in various fields."

To assess personal proneness to risk we used M. Zuckerman's method called "Sensation seeking scale (SSS-V). This method is a shortened version of Form IV of the questionnaire [24], which includes 40 points (10 points for each scale). As a result of filling out the questionnaire, we obtain 4 scales: sensation seeking scale (SSC), intolerance to monotony (ITM), seeking new impressions (SNI), non-adaptive desire for difficulties (NADFD). $\alpha$ Cronbach $=0.55,0.71,0.62,0.61$. Additionally, we verified internal consistency of the questionnaire using correlation analysis.

To assess the degree of manifestation of civil (national) identity, we used the "Civil Identity" method by A. Tatarko [25]. It consists of four scales, each of which is evaluated according to the degree of its manifestation (scale dimension - 5 points according to Lakert scale).

To process primary data we used the statistical software package IBM SPSS Statistics + PS IMAGO PRO, which includes AMOS software, which can be used for modeling with structural equations.

Procedure. First, analysis of the mean and standard deviations of the variables is carried out. Next, results of the correlation analysis are presented. Finally, results of structural modeling with the definition of paths between variables are presented (the most suitable model in terms of dimensions is selected).

Participants. 305 people took part in the study aged $\mathrm{M}=21.2 \mathrm{SD}=2.95$ (35.4\% men), $17.4 \%$ married, $88.9 \%$ city residents (44.6\% residents of big cities, $44.3 \%$ - residents of small towns), education: secondary school $56 \%$, vocational $-14 \%$, Bachelor's degree (specialist) - 26.9\%, Master's degree (and above) $-2.6 \%$.

\section{Results and Discussion}

Table 1 shows that general multi-directional personal activity is positively correlated with all the components of its social activity, which proves that individual social activity components make a practically similar contribution to the general result of this type of activity. General result of multi-directional personal activity is also positively correlated with the majority of types of risky behavior: sensation seeking, new impressions and non-adaptive desire for difficulties.

Individual components of social multi-directional personal activity are interconnected with various types of risky behavior: emotional, motivational and behavioral components are positively interconnected with non-adaptive desire for difficulties, while motivational and behavioral components are positively correlated with seeking for new impressions (see Table 1).

From Table 1 we can see that general multidirectional personal activity is positively interrelated with all the components of its social activity, which points out that its individual components make practically similar contribution to the result of such activity. General result of multidirectional social activity is positively correlated with the majority of risky behavior types: sensation seeking, seeking new impressions, non- adaptive desire for difficulties (see Table 1). Seeking new impressions and sensations obviously widens the sphere of general personal activity, which, in its turn, promotes the increase in the number of social contacts and interactions. At the same time, multiple social contacts with new people determine new strong impressions, sometimes, in the form of sensations. In other words, socially oriented personal activity is one of the tools for implementing the need for new impressions. Some scientists draw the connection between seeking new impressions and sensations with self- 
assessment of satisfaction with one's quality of life, thus supposing, that low level of satisfaction with some aspects of one's life, for example, professional results, family relationships, etc., contributes to the search for new compensatory experiences, thus allowing individuals to expand or change their social environment, switch to other areas of activity where self-esteem and self-fulfillment can be strengthened. At the same time, some researchers point out the fact that this is a complex connection, which is primarily conditioned by social norms and generallyaccepted values [26].

Table 1: Descriptive Statistics and Correlations of Components of Socially Oriented Activity and Proneness to Risky Behavior

\begin{tabular}{|c|c|c|c|c|c|c|c|c|c|c|c|}
\hline $\begin{array}{c}\text { Paramet } \\
\text { ers }\end{array}$ & M & SD & GSA & CSOA & ESOA & $\begin{array}{c}\mathrm{MSO} \\
\mathrm{A}\end{array}$ & $\begin{array}{c}\text { BSO } \\
\text { A }\end{array}$ & $\mathrm{R} 1$ & $\mathrm{R} 2$ & R3 & R4 \\
\hline GSA & 2.21 & 0.55 & 1.00 & $.25 * *$ & $.27 * *$ & $.38 * *$ & $.29 * *$ & $.23 * *$ & .03 & $.17 * *$ & $.12 *$ \\
\hline CSOA & 5.03 & 1.05 & $.25 * *$ & 1.00 & $.42 * *$ & $.43 * *$ & $.46^{* *}$ & .07 & -.07 & -.06 & .09 \\
\hline ESOA & 4.48 & 1.15 & $.27^{* *}$ & $.42 * *$ & 1.00 & $.52 * *$ & $.56^{* *}$ & .09 & -.04 & .00 & $.19 * *$ \\
\hline MSOA & 4.61 & 1.08 & $.38 * *$ & $.43 * *$ & $.52 * *$ & 1.00 & $.57 * *$ & $.12 *$ & -.02 & .03 & $.12 *$ \\
\hline BCOA & 4.99 & 1.02 & $.29 * *$ & $.46^{* *}$ & $.56 * *$ & $.57 * *$ & 1.00 & $.19 * *$ & -.03 & .05 & $.18 * *$ \\
\hline $\mathrm{R} 1$ & 4.88 & 2.41 & $.23^{* *}$ & .07 & .09 & $.12 *$ & $.19^{* *}$ & 1.00 & $.36 * *$ & $.47 * *$ & $.45^{* *}$ \\
\hline $\mathrm{R} 2$ & 4.08 & 2.68 & .03 & -.07 & -.04 & -.02 & -.03 & $.36^{* *}$ & 1.00 & $.22 * *$ & $.26^{* *}$ \\
\hline $\mathrm{R} 3$ & 3.54 & 1.95 & $.17 * *$ & -.06 & .00 & .03 & .05 & $.47 * *$ & $.22 * *$ & 1.00 & $.44 * *$ \\
\hline R4 & 3.55 & 2.19 & $.12 *$ & .09 & $.19^{* *}$ & $.12 *$ & $.18^{* *}$ & $.45^{* *}$ & $.26^{* *}$ & $.44 * *$ & 1.00 \\
\hline
\end{tabular}

Note. The list of abbreviations: GSA - general social activity; CSOA - cognitive component of socially-oriented activity; ESOA - emotional and status component of socially-oriented activity; MSOA - motivational component of socially-oriented activity; BSOA - behavioral component of socially-oriented activity; R1 — sensation seeking; R2 — intolerance to monotony; R3 — seeking new impressions; R4 - nonadaptive desire for difficulties.

General multidirectional socially oriented personal activity is directly correlated with non-adaptive desire for difficulties (see Table 1). The increase in non-adaptive desire for difficulties, which is based on constant search for and overcoming possible difficulties, leads to the increase in general social activity. Through coping with naturally occurring life difficulties, a person with high values on this scale is trying to look for new difficulties, he/she is learning new forms of activity and work, which means that they are exploring the new forms of social interactions, thus increasing their social activity. At the same time, this correlation is not unequivocal. An individual, that is non-adaptively striving to seek for and overcome difficulties, can create these difficulties in social interactions among other things, and be conflict-oriented, inflexible, and unequivocal. However, the desire to overcome difficulties due to constant contacts with people around, discussions regarding the ways of overcoming difficulties, experiments with one's social behavior increases socially oriented personal activity in the long run. Ambiguous role of the non-adaptive desire to find and overcome difficulties has been pointed out by other researchers. Thus, this indicator is manifested in symptom complexes in both low-effective and highly effective subjects in situations of interpersonal situational interaction. Moreover, in the first case, the non-adaptive desire to seek for and overcome difficulties has a negative factor load, while in the second case, this desire can have both negative and positive factor loads. Positive factor load of a non-adaptive desire for difficulties is manifested under condition that planning, modeling, programming, evaluation of results, independence, and high level of general self-regulation are included in social behavior regulation [27].

Separate components of socially oriented multidirectional personal activity are interconnected with various types of risky behavior (see Table 1).

Table 1 shows that motivational and behavioral components of socially oriented personal activity are positively interconnected with sensation seeking and non-adaptive desire for difficulties. These forms of risky behavior are associated with external implementation of personal social activity, which brings us to the conclusion that sensation seeking and non-adaptive desire for difficulties are socially conditioned and maintained in social interaction. On the other hand, personal social activity promotes an increase in the number of social contacts, their duration, which influences strengthening of sensation and evaluation of difficulties under conditions of public behavior and probability of social assessment of this behavior.

Emotional component of personal social activity is interrelated with forms of risky behavior to a lesser degree, while cognitive component is not interrelated with them at all (see Table 1). Only non-adaptive desire for difficulties strengthens the affective processes and conditions in social contacts, makes social activity emotionally rich and vibrant.

The number of children in the parents' family is directly interconnected with motivational and behavioral components of socially oriented personality activity. Committing offenses in one's childhood is negatively 
interconnected with the behavioral component of socially oriented activity in the present. Participation of parents in the public life of the country is positively interconnected with both general socially oriented activity of an individual, as well as with its emotional, motivational and behavioral components. Civil identity correlates with most components of personal socially oriented activity, except for the cognitive component. Respondents' selfesteem concerning the opportunity of participation in public life is positively interconnected with the overall result and all the components of their socially oriented activity. Feeling of uncertainty is inversely related to emotional, motivational and behavioral components of personal socially oriented activity. Personal protest activity has positive interconnections with the overall result of its socially oriented activity.

Table 2 shows that socially oriented personal activity correlates differently with certain conditions and effects of personal socialization. Number of friends is positively correlated with all the components of socially oriented personal activity.

Table 2: Socially-oriented Activity Components in Relation to Conditions and Effects (Results) of Personal Socialization

\begin{tabular}{|c|c|c|c|c|c|}
\hline Parameters & GSA & CSOA & ESOA & MSOA & BSOA \\
\hline Number of friends & .08 & $.13^{*}$ & $.29 * *$ & $.15^{* *}$ & $.22 * *$ \\
\hline Offenses committed in childhood & -.08 & -.02 & .00 & -.06 & $-.12 *$ \\
\hline Number of children in a family & .07 & -.03 & .03 & $.12 *$ & $.14^{*}$ \\
\hline Parents' participation in country's social life & $.28 * *$ & .11 & $.13^{*}$ & $.21 * *$ & $.20 * *$ \\
\hline A country presents opportunities for participation in social life & $.19 * *$ & $.21 * *$ & $.12 *$ & $.21 * *$ & $.20 * *$ \\
\hline $\begin{array}{l}\text { Opportunities for participation in the country's social life } \\
\text { personally for the respondent }\end{array}$ & $.28 * *$ & $.15^{* *}$ & .05 & $.16^{* *}$ & .11 \\
\hline Confusion - lack of certainty & -.02 & -.10 & $-.24 * *$ & $-.17 * *$ & $-.14^{*}$ \\
\hline $\begin{array}{l}\text { Readiness to participate in public protest campaigns with the } \\
\text { purpose of protecting one's rights and freedoms }\end{array}$ & $.21 * *$ & .00 & .02 & .09 & .05 \\
\hline $\begin{array}{l}\text { Readiness to participate in public protest campaigns with the } \\
\text { purpose of disposing of injustice towards a famous person }\end{array}$ & $.14^{*}$ & -.10 & .01 & .10 & .04 \\
\hline $\begin{array}{l}\text { Readiness to participate in public protest campaigns with the } \\
\text { purpose of pay (or any other benefit) rise }\end{array}$ & .11 & .06 & $.14^{*}$ & .01 & -.01 \\
\hline Civil identity & .05 & .09 & $.14^{*}$ & $.31 * *$ & $.15^{* *}$ \\
\hline
\end{tabular}

From Table 2 we can see that socially oriented individual activity is differently correlated with some conditions and effects of individual socialization.

The number of friends (which is a socialization effect) correlates positively with all the components of sociallyoriented personality activity (see table. 2). Socially oriented activity obviously allows an individual to determine the internal grounds for liking potential friends, to increase the likelihood of common interests, to stimulate the knowledge of other people's attitudes and values in a variety of social contacts.

The number of children in parents' family is directly correlated with motivational and behavioral components of socially oriented personal activity (see Table 2), which proves that there is an increase in the desire for external manifestation of social activity in respondents that have siblings. In other words, constant experience of communication with siblings within the family promotes the development of communication, emotional attitude to others in one's social contacts, stimulated the need for social interaction and, later on, positively influences social behavior of an individual.

Committing an offense in one's childhood is negatively correlated with the behavioral component of socially oriented activity in the present (see Table 2), which can be probably explained by durability of negative childhood experiences, non-resolution of conflict relations between an individual and his/her social surrounding, value and social role conflicts with people around.

Parents' participation in public life of the country is a significant factor for both general socially oriented personal activity, and emotional, motivational and behavioral components of social activity (see Table 2). Having seen active position of their parents, children define what is happening in the society more clearly, they learn to express their attitude, react emotionally to social problems, form the motives for their possible solutions. At the same time, cognitive component of socially oriented personal activity is not strengthened, which, possibly, lowers the awareness of social phenomena in children under conditions of high social activity of their parents through acquisition of ready-made knowledge from adult relatives.

Similar interconnections between emotional, motivational and behavioral components of socially oriented activity have been obtained in relation to personal civil identity (see Table 2). Awareness and experience of belonging to a community of citizens of a state allows an individual to strengthen the determination of his/her social activity, 
to manifest it to a greater degree externally, to make the process of social interaction emotionally bright and complete.

From Table 2 we can see that the higher the respondents evaluate the possibility for participation in social life, the more their socially oriented activity is manifested. This shows a certain degree of similarity between social activity and socially oriented activity. When assessing the opportunity for the respondent to personally participate in the public life of the country, the connection with the emotional component of socially oriented activity disappears (see table 2). Perhaps, emotional attitude to certain social phenomena, from the point of view of the respondents, is not typical for social activity, affective background is somewhat leveled, while rational attitude is enhanced due to increased social responsibility.

Protest personal activity is positively correlated with its general social activity (see Table 2). At that, individual components of personal social activity are not correlated with protest tendencies, which allows to come to the conclusion regarding weak differentiation of cognitive, emotional, motivational and behavioral manifestations under conditions of public protest campaigns with the purpose of protecting one's rights and freedoms, or elimination of unfair attitude towards a famous (well-known) person. The emotional component of social activity is directly interconnected with protest moods of the respondents related to the increase in salaries or some other payments, which points out the importance of personal feelings related to the level of material wealth.

From Table 2 we can see that feeling of uncertainty decreases the emotional, motivational and behavioral components of social activity. One should note that cognitive component in this case is independent. It is obvious that under conditions of uncertainty, motivation, emotional/external/behavioral manifestations of social activity are hard for an individual, the focus is primarily on studying the uncertain situation, gathering information, and, due to all of the above, making an attempt to lower the level of uncertainty.

Table 3: Fitness of the Final Model with Data Based on Fitness Indices

\begin{tabular}{lccccccccc}
\hline $\begin{array}{l}\text { Fitness } \\
\text { index } \\
\text { model }\end{array}$ & $\mathrm{X}^{2}$ & $\mathrm{df}$ & $\mathrm{X} 2 / \mathrm{df}$ & $\mathrm{p}$ & GFI & AGFI & CFI & RMSEA & PCLOSE \\
\hline $\begin{array}{l}\text { Model } \\
\begin{array}{l}\text { Final } \\
\text { model }\end{array}\end{array}$ & 99.46 & 58 & 1.71 & 0.001 & 0.953 & 0.926 & 0.950 & 0.48 & 0.541 \\
\hline
\end{tabular}

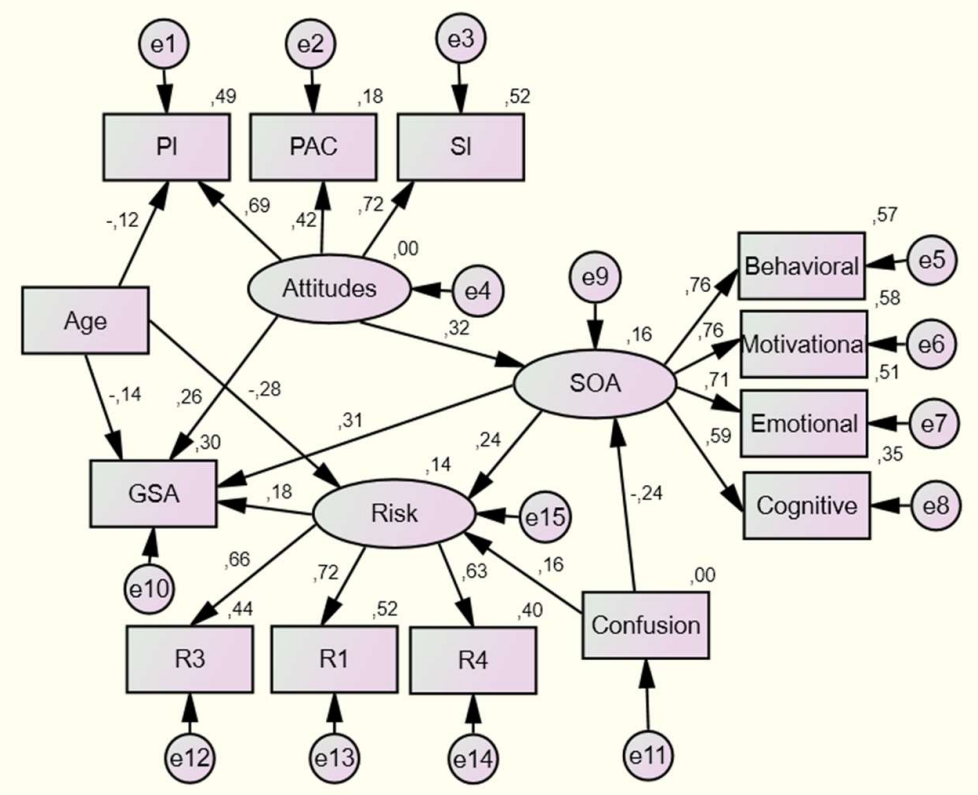

Fig. 1: Model with Suitable Dimensions as a Result of Structural Modeling

Note. The list of abbreviations: GSA - general social activity; SOA - social oriented activity and it's components (cognitive; emotional and status component; motivational; behavioral component of socially-oriented activity); R1 - sensation seeking; R3 — seeking new impressions; $\mathrm{R} 4$ - non- adaptive desire for difficulties; attitudes ( $\mathrm{Pl}$ - opportunities for participation in the country's social life personally for the respondent; $\mathrm{PAC}$ - parents' participation in country's social life; $\mathrm{Sl}$ - a country presents opportunities for participation in social life).

We have been able to obtain a model with suitable dimensions as a result of structural modeling (Table 3), which is presented in Fig. 1. The model shows that three generalized factors (attitudes, components of socially oriented activity, proneness to risk) and one indicator of general (multidirectional) activity form a closed figure 
(quadrangle). The age variable is used as an independent variable for this model. It is negatively interconnected with general activity and risk, which indicates the opposite effect of age on risk and general activity. In other words, the younger the respondent, the more prone he/she is to risk and general social activity. However, there is also a mediation effect between these variables, as we can see from the model, i.e. risk serves as a mediator of the influence of age on overall activity, reducing the direct causal relationship, thereby reducing the value of riskiness in general activity variations. Risk plays a similar role in the direct interconnection between socially oriented activity and general multidirectional activity, i.e. it serves as a mediator of the direct causal relationship between socially oriented and general activity. As we continue the chain, we can see that the direct causal relationship between uncertainty and riskiness is mediated by socially oriented activity; this means that it (SOA) reduces the direct causal correlation between uncertainty and proneness to risk. An important point in this model is the "attitude" variable, which deals with the possibility of social activity in general, among parents and the respondent in particular, which also has a direct effect on overall activity, and is mediated through socially oriented activity, which reduces direct causal connection. This means that attitudes determine the degree of manifestation of socially oriented activity, but in the case of their decreasing effect, it is capable of blocking this effect.

The model explains up to $39 \%$ variation of general multidirectional individual activity, $14 \%$ variation of proneness to risk and $14 \%$ variation of socially oriented activity. $14 \%$ variation of socially oriented activity can be explained by joint influence of the attitudes (positively) and the feeling of uncertainty (negatively); 14\% variation of proneness to risk can be explained by the combined influence of socially oriented activity (positively), a sense of uncertainty and age (negatively); finally, 39\% of the variations of general multidirectional activity are explained by a joint change in attitudes, socially oriented activity, proneness to risk and age (negatively). This data is consistent with previously obtained information. For instance, a study by Belinskaya and Tikhomandritskaya showed that feeling of uncertainty is an important factor in a person's proneness to risky behavior [28]. Studies conducted by Shamionov and Grigoryeva convincingly prove the importance of positive socialization and adaptation of an individual for manifestations of socially oriented activity and its components [3].

\section{Conclusions}

General multidirectional activity of young people is an important factor for participation in social life of a country, as well as personal self-definition in various aspects of social life, i.e. educational, political, Internet-network, etc. Socially oriented personal activity is one of the tools for fulfilling the need for new impressions. The interconnection between general multidirectional socially oriented personal activity and non-adaptive desire for difficulties is ambiguous: on the one hand, through coping with difficulties that naturally occur in one's life a person learns the new forms of activity, new types of work, as well as the new spheres of social interactions, thus, increasing his/her own social activity; on the other hand, a person that is striving to search for and overcome difficulties can be the one that creates these difficulties in social interactions.

Sensation seeking and non-adaptive desire for difficulties are associated with fulfillment of personal social activity in one's external behavior, which brings us to conclusion that searching for new sensations and non-adaptive desire for difficulties are socially conditioned and maintained in social interactions.

Socially oriented personal activity is interconnected with certain conditions and effects of personal socialization in various ways, i.e. all the components of socially oriented personal activity are positively associated with the number of friends; emotional, motivational and behavioral components, as well as the general result of socially oriented activity are positively interrelated with the participation of the respondents' parents in the social life of the country and personal civil identity.

Emotional attitude to certain social phenomena is not characteristic of social activity, its affective background is somewhat leveled, and a rational attitude is enhanced by increasing social responsibility.

Personal protest activity is positively interrelated with personal general social activity. At the same time, individual components of personal social activity are not interconnected with protest trends, which brings us to the conclusion that there is weak differentiation of cognitive, emotional, motivational and behavioral manifestations under conditions of public protest campaigns.

Under conditions of uncertainty motivation, emotional, external, and behavioral manifestations of social activity are quite complex for an individual, his/her attention is focused primarily on studying an uncertain situation, gathering information and, due to this, an attempt to reduce the uncertainty.

Sructural modeling allows to conclude that the following factors are extremely important for general activity (1) coordinated effect (influence) of attitudes regarding the possibility of social activity in the country and socially oriented activity; (2) age effect (negatively) and socially-oriented activity through proneness to risk (independent of one another).

\section{Funding}

This research was funded by Russian Science Foundation, grant № 18-18-00298 


\section{References}

[1] Kudinov, S.S. Social'naja aktivnost' kak osnova samorealizacii lichnosti [Social activity as the basis of selfidentity]. Akmeologija [Acmeology] 2014, S1-2, 124-125.

[2] Abul'hanova-Slavskaja, K. A. Psihologija i soznanie lichnosti (problemy metodologii, teorii i issledovanija real'noj lichnosti) [Psychology and consciousness of the person (problems of methodology, theory and research of the real person)]. Moscow; Voronezh, 1999. $224 \mathrm{p}$.

[3] Shamionov, R.M.; Grigoryev, A.V. The Image of Socially Active Individual in the Representations of Student Youth. International Journal of Cognitive Research in Science, Engineering and Education 2019, 7(1), 15-20. https://doi.org/10.5937/ijcrsee1901015S

[4] Shamionov, R.M.; Grigoryeva, M.V.; Grigoryev, A.V. World Assumptions and Youth Identity as Predictors of Social Activity Preferences. Psychology in Russia: State of the Art 2019, Vol. 12(2), 115-133. https://doi.org/10.11621/pir.2019.0209

[5] Arendachuk, I.V. Dynamics of Value and Meaning Characteristics of Social Activity of Modern Youth. RUDN Journal of Psychology and Pedagogics 2018, 15(3), 287-307. https://doi.org/10.22363/2313-1683-201815-3-287-307

[6] McFarland, D.A.; Thomas, R.J. Bowling Young: How Youth Voluntary Associations Influence Adult Political Participation. American Sociological Review 2016., 71(3), 401-425.

[7] Brown, C.L.; Gibbons, L.E.; Kennison, R.F.; Robitaille, A.; Lindwall, M.; Mitchell, M.B.; Shirk, S.D.;Atri, A.; Cimino, C.R.; Benitez, A.; MacDonald, S.W.S.; Zelinski, E.M.; Willis, S.L.; Schaie Warner, K.; Johansson, B.; Dixon, R.A.; Mungas, D.M.; Hofer, S.M.; Piccinin, A.M. Social Activity and Cognitive Functioning Over Time: A Coordinated Analysis of Four Longitudinal Studies. Journal of Aging Research 2012., 1. Article ID 287438, 12 p. https://doi.org/10.1155/2012/287438

[8] Oosterhoff, B.; Ferris, K.A.; Metzger, A. Adolescents' Sociopolitical Values in the Context of Organized Activity Involvement. Youth \& Society 2017, 49(7), 947-967.

[9] Krysko, V.G. Sotsial'naya psikhologiya: slovar'-spravochnik. Minsk: Kharvest 2001. 688 p. (In Russ.)

[10] Kondrateva, E. V. Formation of social activity in student's age. Russian journal of social work 2017, 4, 114118.

[11] Moiseev, A. S. Psihologicheskie tipy social'nogo samoopredelenija predstavitelej srednego klassa moskovskogo regiona [Psychological types of social self-determination of representatives of the middle class of the Moscow region] [Electronic resource]. Informacionno-gumanitarnyj portal "Znanie. Ponimanie. Umenie" [Information and humanitarian portal "Knowledge. Understanding. Skill"] 2013, 1. URL: http://www.zpujournal.ru/e-zpu/2013/1/Moiseev Social-Self-determination-Middle-Class/ (14.04.2018).

[12] Mikhailova, E.V.; Skogorev A.P. Protest as form of civil activity in modern Russia. Vlast' 2017, 25(1), 54 59. (In Russ.)

[13] Savrasova-V'un, T. Social networks and their role in development of civic activity of the Ukrainian youth. Communication today 2017, 8(1), 104-112.

[14] Seigfried-Spellar, K.C.; Lankford, C.M. Personality and online environment factors differ for posters, trolls, lurkers, and confessors on Yik Yak. Personality and individual differences 2018, 124, 54-56. https://doi.org/10.1016/j.paid.2017.11.047

[15] Koo, H. J.; Woo, S.; Yang, E.; Kwon, J.H. The Double Meaning of Online Social Space: Three-Way Interactions Among Social Anxiety, Online Social Behavior, and Offline Social Behavior. Cyberpsychology behavior and social networking 2015, 18 (9): 514-520. https://doi.org/10.1089/cyber.2014.0396

[16] Sherman, L.E.; Greenfield, P. M.; Hernandez, L.M.; Dapretto, M. Influence Via Instagram: Effects on Brain and Behavior in Adolescence and Young Adulthood. Child development 2018, 89 (1), 37-47. https://doi.org/10.1111/cdev.12838

[17] Jost, J.T.; Barbera, P.; Bonneau, R.; Langer, M.; Metzger, M.; Nagler, J.; Sterling, J.; Tucker, J.A. How Social Media Facilitates Political Protest: Information, Motivation, and Social Networks. Political psychology 2018. 39(1), 85-118. https://doi.org/10.1111/pops.12478

[18] James, B.D.; Wilson, R.S.; Barnes, L.L.; Bennett, D.A. Late-life social activity and cognitive decline in old age. Journal of the International Neuropsychological Society 2011, 17(6). P. 998-1005.

[19] Park, H.K.; Chun, S.Y.; Choi, Y.; Lee, S.Y.; Kim, S.J.; Park, E.C. Effects of social activity on health-related quality of life according to age and gender: an observational study. Health Qual Life Outcomes 2015, 13. 140 .

[20] Russo, S.; Amna, E. When political talk translates into political action: The role of personality traits. Personality and individual differences 2016, 100: 126-130. https://doi.org/10.1016/j.paid.2015.12.009

[21] Shiratuddin, N.; Hassan, S.; Mohd Sani, M.A.; Ahmad, M.K.; Khalid, K.A.; Abdull Rahman, N.L.; Ahmad, N.S.Y. Media and youth participation in social and political activities: Development of a survey instrument and its critical findings. Pertanika Journal of Social Sciences and Humanities 2017, 25, 1-19.

[22] Zagranichniy, A. Study of the correlation of factors affecting frequency of social activity transfer from virtual environment to real-world environment and vice versa. SHS Web Conf. [Trends in the Development of Psycho- 
Pedagogical Education in the Conditions of Transitional Society (ICTDPP-2019)] 2019, 70, 08046(5). https://doi.org/10.1051/shsconf/20197008046

[23] Shamionov, R.M.; Grigoryeva, M.V. Technique for Diagnostic Assessment of Socially-Oriented Activity Components. Sibirskiy Psikhologicheskiy Zhurnal - Siberian journal of psychology 2019, 74, $26-41$. https://doi.org/10.17223/17267080/74/2

[24] Zuckerman, M. Sensation Seeking: Beyond the Optimal Level of Arousal. Hillsdale, NJ: Lawrence Erlbaum Associates 1979.

[25] Tatarko, A.N. Social capital as an object of psychological research. Moscow: MAKS press 2011.

[26] Lafi, S.G.; Pitelskaite-Markovene, M.E. Seeking new sensations; place and significance in psychological self-fulfillment. Urgent problems of humanitarian and natural sciences 2014, 9, 379-390

[27] Belykh, T.V.; Mairamian, A.M. Structural and functional characteristics of the subject of interpersonal situational interaction. Humanization of education 2016, 2, 73-82

[28] Belinskaya, E. P.; Tikhomandritskaya, O.A. Social psychology of personality. Moscow: Publishing center "Academy" 2009 